\title{
Weight Calculation and Index Ranking Study of MADM Based on AHP Optimized by Topsis
}

\author{
Chen Ran ${ }^{1,2, a}$, Lian Guangyao ${ }^{2, b}$, Shao Shuai ${ }^{1, c}$, Li Huijie ${ }^{2, d}$, Li Xingrü ${ }^{2, e}$
}

\author{
${ }^{1}$ Mechanism Engineering College, Heping West Road NO.97 ${ }^{\text {th }}$, Shijiazhuang 050000, China \\ ${ }^{2}$ New Technological Research Institute, Beixin Road N0.169 ${ }^{\text {th }}$,Shijiazhuang 050003, China

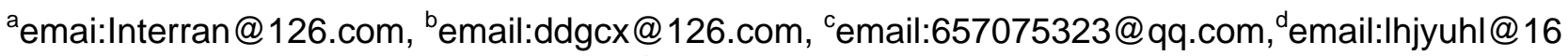 \\ 3.com, email;lixingru@163.com
}

\begin{abstract}
Keywords: multiple attribute decision making (MADM), Analytic Hierarchy Process, Topsis, Index ranking, Weight calculation

Abstract. A analytic hierarchy process optimized by topsis was presented aiming at the disadvantages that there are inconsistency and too much subjectivity in the existing multiple attribute decision making(MADM) methods when dealing with the weight calculation and index ranking problems. This method utilizes topsis for index ranking at first, then the weight calculating could according to the ranking results and expert system by the utilize of analytic hierarchy process. Case study indicates that the above method could efficiently weaken the subjectivity, strengthen the consistency of the analytic hierarchy process, and which is easy to be utilized in engineering tests.
\end{abstract}

\section{Introduction}

Multiple attribute decision making(MADM) is an important approach in modern decision science, which refers to the decision problem of selecting the best schedule or ranking the schedules by considering multiple attributes. Theories and approaches of MADM have been widely utilized in many fields, such as engineering, technology, economy, management, military etc. ${ }^{[1-2]}$.MADM is usually utilized to solve the two kinds of the problems such as evaluation and selection through index ranking and weight calculating in reliability \& testability verification test ${ }^{[3]}$. The main methods to deal with the problem are Elimination et choix traduisant laréalité(ELECTRE) ${ }^{[4]}$,Multi-Attribute Value Theory(MAVT) ${ }^{[5]}$, and Quality Function deployment(QFD),Analytic Hierarchy Process(AHP),Topsis that combined with Delphi method etc. ${ }^{6-9]}$ at present. However, ELECTRE is based on priority between attributes that different from general function model. MAVT is a bit complex which seldom used in engineering tests. QFD often utilize the 1-5 or 1-9 integer numbers in ranking attributes, so that there is a certain subjectivity and randomness. There is a reverse problem in scheduling problems in AHP, so the consistency is still controversial ${ }^{[7]}$.Topsis usually aim at index ranking, not for weight calculating ${ }^{[8,9]}$.Therefore, presenting a weight calculating and index ranking method of MADM which is convenient and applicable to engineering test is an urgent problem.

AHP optimized by topsis has been put forward in this paper, and a failure samples allocation operation for a testability verification test of a certain equipment would be taken as an example to verify the presented method.

\section{AHP Optimized by Topsis}

The basic principle of the algorithm. First, Delphi method has been utilized to carry out the expert scoring, and then the ideal point method would be applied to rank the expert scoring in this algorithm. After obtaining the ranking result, AHP would be utilized to calculate the weights. Assigning the judgment matrix by expert system should take the ranking result as a basis, so that the subjective and randomness could be weaken, and the consistency could be strengthen.

Quantitative Index Ranking Based on Topsis. The basis of Topsis is establishing the ideal solution and negative-ideal solution. The distance relation between the target and ideal/negative-ideal 
solution named $S^{*}$ and $S^{-}$is taken as the judgment basis $C^{*[8-9]}$. The ideal solution indicates the nearest value of the distance from the optimal solution of all the attribute index in all of the candidate scheme, and the negative-ideal solution indicates the farthest value of the distance from the optimal solution of all the attribute index in all of the candidate scheme. $\mathrm{C}^{*}$ is the function of ideal solution and negative-ideal solution that shown in Eq.1.

$$
C^{*}=\frac{S^{-}}{S^{-}+S^{*}}
$$

Assuming that there are $k$ experts, $\mathrm{m}$ attribute indicators, the scoring form of these attribute indicators are shown in Table 1.

Table 1 Quantitative scoring of each attribute index

\begin{tabular}{ccccccc}
\hline $\begin{array}{c}\text { Attribute } \\
\text { index }\end{array}$ & \multicolumn{4}{c}{ Expert scoring } & Judgment & $\begin{array}{c}\text { The topsis } \\
\text { banking }\end{array}$ \\
\hline 1 & $a_{11}$ & $a_{12}$ & $\ldots$ & $a_{1 k}$ & $A_{1}$ & $B_{1}$ \\
2 & $a_{21}$ & $a_{22}$ & $\ldots$ & $a_{2 k}$ & $A_{2}$ & $B_{2}$ \\
$\ldots$ & $\ldots$ & $\ldots$ & $\ldots$ & $\ldots$ & $\ldots$ & $\ldots$ \\
$\mathrm{m}$ & $a_{m 1}$ & $a_{m 2}$ & $\ldots$ & $a_{m k}$ & $A_{m}$ & $B_{m}$ \\
\hline
\end{tabular}

The highest score is considered to be $x_{M}$, and the lowest score is considered to be $x_{0}$. The highest score is considered to be $x_{M}$,and the lowest score is considered to be $x_{0}$.According to Minkowski distance calculation method ${ }^{[10]}$, the calculation of $\mathrm{S}^{*}$ and $\mathrm{S}^{-}$are shown in Eq.2 \& Eq.3.

$$
\begin{aligned}
& S^{*}=\left|F(x)-F\left(x_{M}\right)\right|=\left\{\sum_{i}\left[F\left(x_{i, j}\right)-F\left(x_{M}\right)\right]^{P}\right\}^{\frac{1}{p}} ; x_{i, j}=a_{i j} \\
& S^{-}=\left|F(x)-F\left(x_{0}\right)\right|=\left\{\sum_{i}\left[F\left(x_{i, j}\right)-F\left(x_{0}\right)\right]^{P}\right\}^{\frac{1}{p}} ; x_{i, j}=a_{i j}
\end{aligned}
$$

In the above formulas, non-inferior solution could be obtained if $P \in(1,+\infty)$. Define different $\mathrm{P}$ value may realize the selection of distance space. For example, $\mathrm{P}=1$ indicates the Hamming distance or absolute distance , $P=2$ indicates the Euclidean distance, $P \rightarrow \infty$ indicates the Chebyshev distance. The ranking of the indexes based on the descending order of $\mathrm{C}^{*}$.

Weight calculation based on AHP. AHP is a simple and convenient method for quantitative analysis of non quantitative events in system engineering. It is proposed by T.L.Saaty and quickly applied to the system ${ }^{[11]}$.AHP using 1-9 and its reciprocal scaling method in quantitative calculation, calculating the importance of their goals through the importance of the two-two comparison between the indicators.

Establishing the judgment matrix like Eq.4.

$$
\mathbf{L}_{i, j(\mathrm{~m} \times \mathrm{m})}=\left[\begin{array}{rrrr}
l_{1,1} & l_{1,2} & \mathrm{~K} & l_{1, m} \\
l_{2,1} & l_{2,2} & \mathrm{~K} & l_{2, m} \\
\mathrm{M} & \mathrm{M} & \mathrm{O} & \mathrm{M} \\
l_{m, 1} & l_{m, 2} & \mathrm{~K} & l_{m, m}
\end{array}\right]
$$

Where, $l_{i j}$ indicates the importance of $i$ than $j$. Obviously $l_{i j}>0, l_{i i}=1, l_{i j}=1 / l_{j i}$.

Operating the importance level assignment of each element in Eq.4 according to the ranking results obtained by topsis and utilizing the expert system. The rules of assignment are shown in Table2.

After getting the judgment matrix, normalizing it at first as shown in Eq.5.

$$
\delta_{i j}=\frac{l_{i j}}{\sum_{i=1}^{m} l_{i j}{ }^{2}} ; i, j=1,2, \ldots, m
$$


The weight calculation is shown in Eq.6.

$$
\omega_{i}=\frac{\sum_{j=1}^{m} \delta_{i j}}{\sum_{i=1}^{m} \sum_{j=1}^{m} \delta_{i j}} ; i, j=1,2, \ldots, m
$$

Finally, the weight $\omega_{1} \omega_{2} \ldots \omega_{m}$ of each factor could be obtained.

Table 2 The importance of elements pairwise comparison and whose assignment

\begin{tabular}{ccc}
\hline Serial number & Importance level & Assignment \\
\hline 1 & $i$ is extremely less important than $j$ & $1 / 9$ \\
2 & $i$ is strongly less important than $j$ & $1 / 7$ \\
3 & $i$ is obviously less important than $j$ & $1 / 5$ \\
4 & $i$ is slightly less important than $j$ & $1 / 3$ \\
5 & $i$ is equally less important than $j$ & 1 \\
6 & $i$ is slightly more important than $j$ & 3 \\
7 & $i$ is obviously more important than $j$ & 5 \\
8 & $i$ is strongly more important than $j$ & 7 \\
9 & $i$ is extremely more important than $j$ & 9 \\
\hline
\end{tabular}

Consistency discussion. In order to examine the rationality of judgment matrix, Consistency ratio CR is utilized to operating consistency demonstration as shown in Eq.7.

$$
C R=\frac{C I}{R I}=\frac{\lambda_{\max }-n}{R I(n-1)}
$$

Where $\lambda_{\max }$, is the biggest characteristic root of the judgment matrix,RI is the mean value of random consistency index whose value is related to the judgment matrix order shown in Table3.

Table 3 Value of $R I$

\begin{tabular}{ccccccc}
\hline Order number & 4 & 5 & 6 & 7 & 8 & 9 \\
\hline$R I$ & 0.90 & 1.12 & 1.24 & 1.32 & 1.41 & 1.45 \\
\hline
\end{tabular}

When $C R<0.1$, the judgment matrix is considered consistent, Otherwise, it needs to be adjusted until it meets the condition ${ }^{[11]}$.

\section{Case study}

Fundamental state of the test and the under test units. R.A failure samples allocation operation of a testability verification test for an system is taken as the example for case study.Failure samples allocation is one of the key technologies in testability verification test, through which a certain number of samples are selected from fault pattern set and allotted to each function unit of the system after determining the sample size of the test.

The under test unit(UUT) is the core of a control execution system in which data transfer with the superior computer and information interchange with the subordinate computer could be achieved, so that logical relation processing as well as state control and detection of the whole control execution process could be successfully implemented. The functions of the UUT is shown by Fig 1.

There are 3 main functional units in the UUT, including power supply unit, module support unit and processing unit. While in the power supply unit, the input large voltage DC power supply can be converted to $+5 \mathrm{~V},+12 \mathrm{~V}$ and $-12 \mathrm{~V}$ power supply required for each functional unit. There is a processor in the processing unit in which data processing, logic relation processing and state control could be realized. Module support unit including A/D conversion function unit and asynchronous / synchronous communication function unit that can provide support and implementation for the processor and Build-in-test(BIT) circuit. 
Factors that need to be considered when operating samples allocation based on weighted method including failure rate, failure effect, mean time-to-repair(MTTR), and test cost $C_{t}$. The dimensionless value of the above factors are shown in Table4.

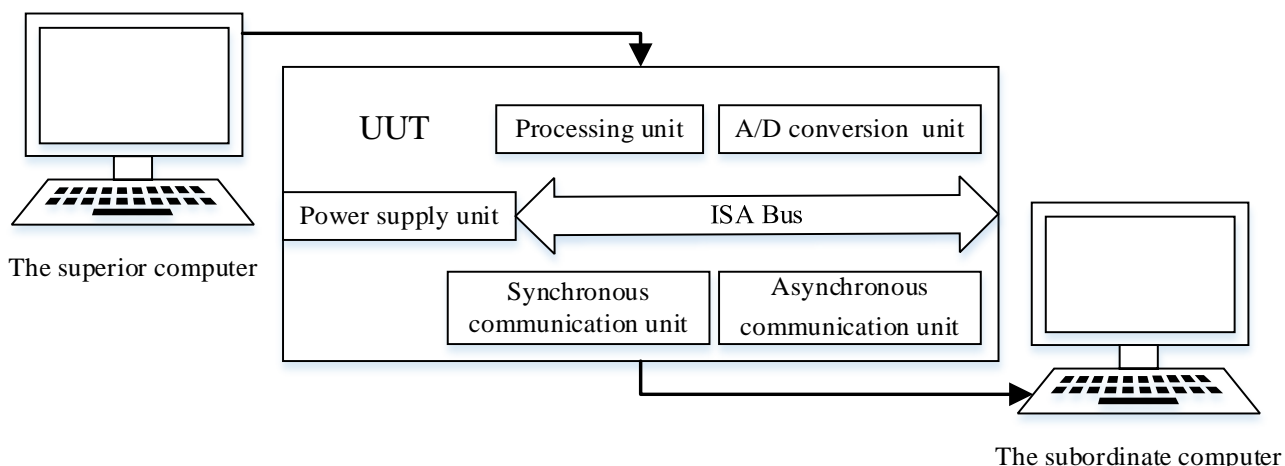

Fig 1 Function block diagram of the UUT

Table 4 The dimensionless value of the factors that influence samples allocation

\begin{tabular}{ccccccc}
\hline Function units & $\begin{array}{c}\text { Failure } \\
\text { rate }\end{array}$ & $\begin{array}{c}\text { Failure } \\
\text { effect }\end{array}$ & MTTR & 1/MTTR Test cost & $1 / \mathrm{C}_{\mathrm{t}}$ \\
\hline Power supply unit & 0.19 & 5 & 25 & 0.0400 & 200 & 0.0050 \\
Processing unit & 0.12 & 4 & 20 & 0.0500 & 200 & 0.0050 \\
A/D conversion unit & 0.12 & 2 & 15 & 0.0667 & 220 & 0.0045 \\
Asynchronous communication unit & 0.18 & 5 & 15 & 0.0667 & 250 & 0.0040 \\
Synchronous communication unit & 0.15 & 3 & 15 & 0.0667 & 150 & 0.0067 \\
Sum & 0.76 & 19 & - & 0.2900 & - & 0.0252 \\
\hline
\end{tabular}

Weight Calculation Based on Analytic Hierarchy Process Optimized by Topsis. Scoring each influencing factor by the expert system, then ranking these factors by topsis according to Eq.1, Eq.2 \& Eq.3. Scoring and ranking of expert systems for each factors based on topsis are shown in Table5.

Table 5 Scoring and ranking of expert systems for each factors based on topsis

\begin{tabular}{|c|c|c|c|c|c|c|}
\hline \multirow{2}{*}{ Attribute index } & & Expert & scoring & & \multirow{2}{*}{ Judgment basis value } & \multirow{2}{*}{ The topsis ranking } \\
\hline & Expert1 & Expert2 & Expert3 & Expert4 & & \\
\hline Failure rate & 7 & 8 & 6 & 7 & 0.695368789 & 2 \\
\hline Failure effect & 9 & 8 & 8 & 6 & 0.757898276 & 1 \\
\hline MTTR & 3 & 4 & 4 & 3 & 0.351628705 & 3 \\
\hline Test cost & 2 & 4 & 3 & 4 & 0.330295985 & 4 \\
\hline
\end{tabular}

Establish the judgment matrix which is shown in Eq.8.

$$
\mathbf{L}_{i, j(4 \times 4)}=\left[\begin{array}{llll}
1.000 & 0.333 & 3.000 & 5.000 \\
3.000 & 1.000 & 5.000 & 7.000 \\
0.333 & 0.200 & 1.000 & 3.000 \\
0.200 & 0.143 & 0.333 & 1.000
\end{array}\right]
$$

And then calculate the weight of the factors according to formula(5)\&(6),so that the weights are shown in Table6.

Table 6 Weight of the factors calculated through AHP optimized by Topsis

\begin{tabular}{ccccc}
\hline Factors & Failure rate & Failure effect & MTTR & Test cost \\
\hline Weight of each factor & $\omega_{1}=0.296$ & $\omega_{2}=0.507$ & $\omega_{3}=0.144$ & $\omega_{4}=0.053$ \\
\hline
\end{tabular}

Weight Calculation Based on Traditional AHP. Establish the judgment matrix as shown in Eq.9 according to the rules in Table2 and expert system. 


$$
\mathbf{L}_{i, j(4 \times 4)}=\left[\begin{array}{cccc}
1.000 & 0.333 & 5.000 & 5.000 \\
3.000 & 1.000 & 7.000 & 5.000 \\
0.200 & 0.143 & 1.000 & 3.000 \\
0.200 & 0.200 & 0.333 & 1.000
\end{array}\right]
$$

Then calculate the weight of each factor as shown in Table7.

Table 7 Weight of each factor calculated through traditional AHP

\begin{tabular}{ccccc}
\hline Factors & Failure rate & Failure effect & MTTR & Test cost \\
\hline Weight of each factor & $\omega_{1}=0.339$ & $\omega_{2}=0.479$ & $\omega_{3}=0.130$ & $\omega_{4}=0.052$ \\
\hline
\end{tabular}

Analysis and Comparison. If the test cost factor was put out of consideration, the re-ranking of the factors via AHP optimized by Topsis is shown in Table8.The judgment matrix is shown in Eq.10, and the re-calculated weights of each factor are shown in Table9.

Table 8 Re-ranking of the factors via AHP optimized by topsis

\begin{tabular}{|c|c|c|c|c|c|c|c|}
\hline \multicolumn{2}{|c|}{ Attribute index } & Expert1 & $\begin{array}{r}\text { Expert } \\
1 \text { Expert2 }\end{array}$ & $\begin{array}{l}\text { scoring } \\
\text { Expert3 }\end{array}$ & Expert4 & \multicolumn{2}{|c|}{ Judgment basis value The topsis ranking } \\
\hline \multirow{3}{*}{\multicolumn{2}{|c|}{$\begin{array}{c}\text { Failure rate } \\
\text { Failure effect } \\
\text { MTTR }\end{array}$}} & 7 & 8 & 6 & 7 & 0.695368789 & 2 \\
\hline & & 9 & 8 & 8 & 6 & 0.757898276 & 1 \\
\hline & & 3 & 4 & 4 & 3 & 0.351628705 & 3 \\
\hline \multirow{3}{*}{$-_{i, j(3 \times 3)}=$} & {$[1.000$} & 0.333 & 3.000 & & & & \\
\hline & 3.000 & 1.000 & 5.000 & & & & \\
\hline & 0.333 & 0.200 & 1.000 & & & & \\
\hline
\end{tabular}

Table 9 Re-calculated weight via AHP optimized by topsis

\begin{tabular}{cccc}
\hline Factors & Failure rate & Failure effect & MTTR \\
\hline Re-calculated weight & $\omega_{1}=0.291$ & $\omega_{2}=0.605$ & $\omega_{3}=0.103$ \\
\hline
\end{tabular}

However, judgment matrix obtained by traditional AHP is shown in Eq.11, and the weights are shown in Table10.

$$
\mathbf{L}_{i, j(3 \times 3)}=\left[\begin{array}{ccc}
1.000 & 0.333 & 5.000 \\
3.000 & 1.000 & 7.000 \\
0.200 & 0.143 & 1.000
\end{array}\right]
$$

Table 10 Re-calculated weight via traditional AHP

\begin{tabular}{cccc}
\hline Factors & Failure rate & Failure effect & MTTR \\
\hline Re-calculated weight & $\omega_{1}=0.339$ & $\omega_{2}=0.589$ & $\omega_{3}=0.072$ \\
\hline
\end{tabular}

Calculate the relative weights, then compare them and the re-calculated weights via variance. The results of the comparison are shown in Table11.

Table 11 The analyse results comparison

\begin{tabular}{cccccc}
\hline Approach & Factors & Failure rate & Failure effect & MTTR & Variance \\
\hline \multirow{2}{*}{ Traditional AHP } & relative weights & 0.358 & 0.505 & 0.137 & \multirow{2}{*}{0.017} \\
Re-calculated weight & 0.339 & 0.589 & 0.072 & \\
AHP optimized & relative weights & 0.313 & 0.536 & 0.152 & \multirow{2}{*}{0.007} \\
by topsis & Re-calculated weight & 0.291 & 0.605 & 0.103 & \\
\hline
\end{tabular}

Obviously, the variance of AHP optimized by topsis is much less than Traditional AHP. So it could be pointed out that the expert system of traditional AHP might cause subjective, and which could be decreased by AHP optimized by topsis. 


\section{Discussion}

The under-performed consistency problem in AHP could be traced back to the expert system that utilized to determine the value of each data when establishing the judgment matrix . The subjective of expert system as well as the lack of sort basis that might cause a too casual assignment of the importance of elements pairwise comparison. However, topsis could provide the basis of the importance of elements pairwise comparison and whose assignment by a scientific ranking.

\section{Summary}

An AHP optimized by topsis has been presented to solve the under-performed consistency problem caused by the subjective of expert system when establishing the judgment matrix in AHP. There two advantages in AHP optimized by topsis.

(1) Scientific ranking could be accomplished via the expert system.

(2) The subjective of expert system could be efficiently decreased when calculating the weights.

\section{Acknowledgements}

This work was financially supported by National Defence Pre-research Foundation (51327030104).

\section{References}

[1] Hwang, Ching Lai, and K. Yoon. "Multiple Attribute Decision Making."Lecture Notes in Economics \& Mathematical Systems 186(1981).

[2]Tzeng, Gwo Hshiung, and J. J. Huang. "Multiple attribute decision making." Crc Press Boca Raton Fl (2011).

[3]Wei, Gui Wu. "Gray Relational Analysis Method For Intuitionistic Fuzzy Multiple Attribute Decision Making." Expert Systems with Applications38.9(2011):11671-11677.

[4]Rouyendegh, Babak Daneshvar, and T. E. Erkan. "An Application of the Fuzzy ELECTRE Method for Academic Staff Selection." Human Factors \& Ergonomics in Manufacturing 23.2(2013):107 - 115.

[5]Ferretti, Valentina, and E. Comino. "An integrated framework to assess complex cultural and natural heritage systems with Multi-Attribute Value Theory." Journal of Cultural Heritage 16.5(2015):688-697.

[6]Akao, Y. "Quality function deployment QFD: Integrating customer requirements into product design." Produktionsmanagement 1(1990):96-100.

[7]Pengcheng Zhang, and Weijuan Li. "Appraise Harmony about Relationship between Oil Companies and Local." Sustainable Development 01.01(2011).

[8]Kilpeläinen, Antti, et al. "A hybrid method of FEM, modified NSGAII and TOPSIS for structural optimization of sandwich panels with corrugated core." Journal of Sandwich Structures \& Materials 16.4(2014):398-417.

[9]Lai, Young Jou, T. Y. Liu, and C. L. Hwang. "TOPSIS for MODM."European Journal of Operational Research 76.3(1994):486-500.

[10]Vega, Alberto, et al. "Notes on Dependent Attributes in TOPSIS $\hat{\gamma}^{\wedge}$."Procedia Computer Science 31(2014):308-317.

[11]Saaty, Thomas L. "Basic theory of the analytic hierarchy process: how to make a decision." Revista De La Real Academia De Ciencias Exactas Físicas Y Naturales 93.4(1999):págs. 395-423. 